\title{
Stereoselective Synthesis of Constrained Oxacyclic Hydroxyethylene Isosteres of Aspartic Protease Inhibitors \\ - Aldol and Mukaiyama Aldol Methodologies for Branched Tetrahydrofuran 2-Carboxylic Acids
}

Stephen Hanessian, ${ }^{\dagger}$ Yihua Hou, Malken Bayrakdarian, Marina Tintelnot-Blomley
${ }^{\dagger}$ Department of Chemistry, Université de Montréal, C.P. 6128, Station Centre-ville, Montréal, P.Q., H3C $3 J 7$ Canada, phone (514) 343-6738, fax (514) 343-5728, Email: stephen.hanessian@umontreal.ca
${ }^{*}$ Novartis Institutes of Biomedical Research, Novartis Pharma A G , Postfach CH-4002, Basel, Switzerland
Email: marina.tintelnot-blomley@pharma.novartis.com

\section{Supporting Information}

1. Experimental Section;

p. S2

2. Copies of NMR spectra; 3a, 4a, 5a, 6c, 6d, 10, 12, 13, 14, 15, 17, 18c, 21c p. S3-S30

3. HPLC data; $21 \mathrm{c}$

p. S31

4. X-ray CIF files; compounds 3a, 4a, 4c, 5b, 6c, 9, 13 


\section{Experimental section}

Solvents such as $\mathrm{THF}$, ether, toluene, and $\mathrm{CH}_{2} \mathrm{Cl}_{2}$ were dried using the dry alumina column method. All reactions were performed under nitrogen or argon atmosphere. NMR $\left({ }^{1} \mathrm{H},{ }^{13} \mathrm{C}\right)$ spectra were recorded at 300 and $400 \mathrm{MHz}$ in $\mathrm{CDCl}_{3}$ or $\mathrm{CD}_{3} \mathrm{OD}$ or $\mathrm{D}_{2} \mathrm{O}$ with solvent resonance as the internal standard. Low- and high-resolution mass spectra were recorded on using fast atom bombardment $(\overline{F A B})$. Optical rotations were recorded in a 1 dm cell at ambient temperature. Analytical thin-layer chromatography was performed precoated silica gel plates. Flash column chromatography was performed using (40-60 $\mu \mathrm{m})$ silica gel under gentle pressure. MPLC analysis was performed on reverse phase 0 18 columns. All melting points are uncorrected. 


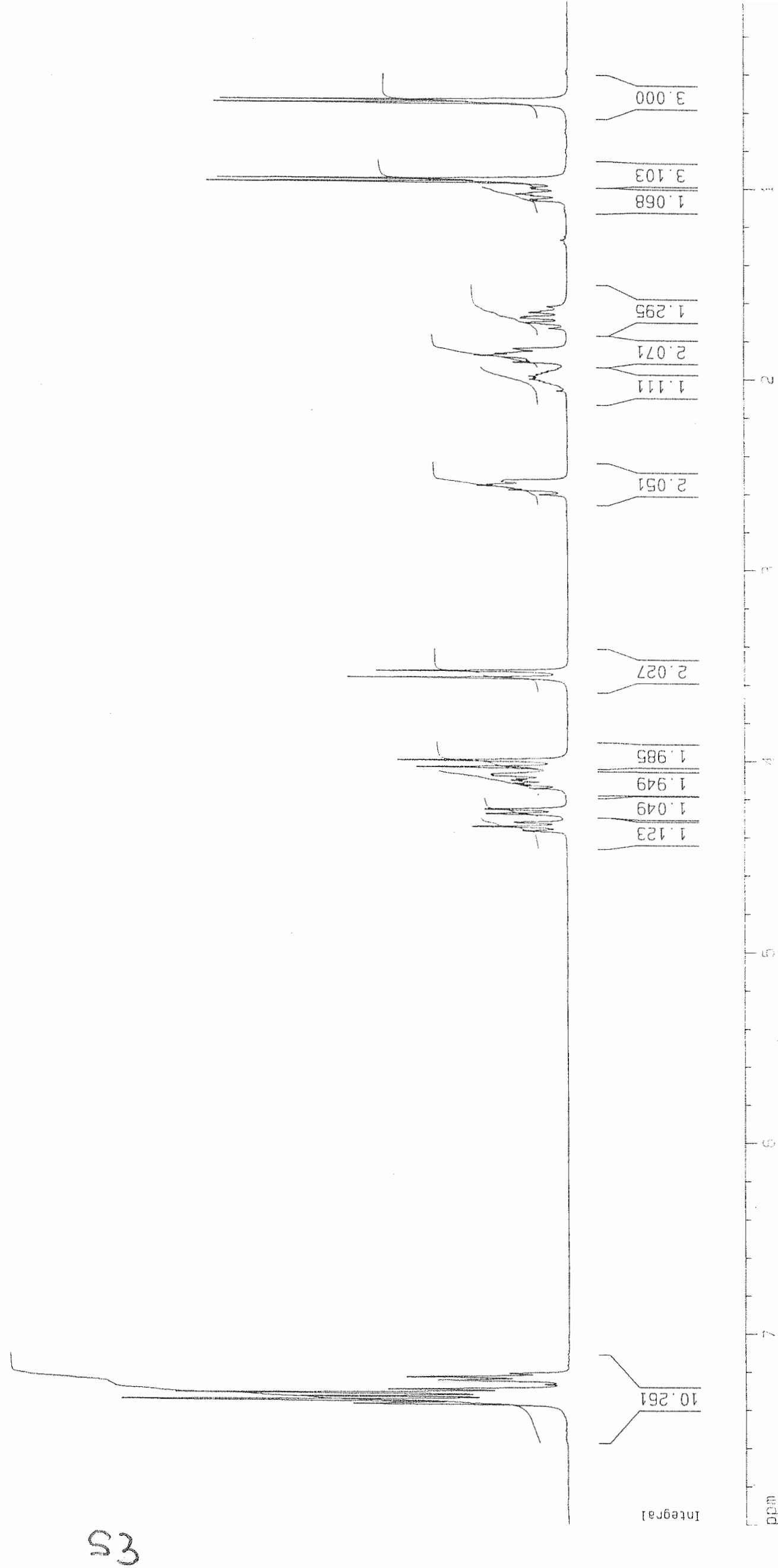




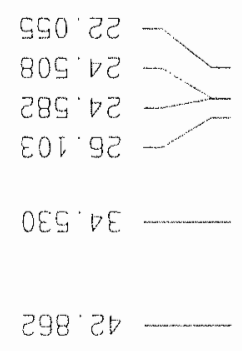

8L8 05
v6 99

V8: $19 \ldots$

$66 \mathrm{e}^{\circ}$

$99+\angle L$

E V $L L \quad=$

$.6 \angle L$
190 L2

$\angle 698 \mathrm{el}$

$\angle O E^{\circ}$ '́巳i

5.90 .161

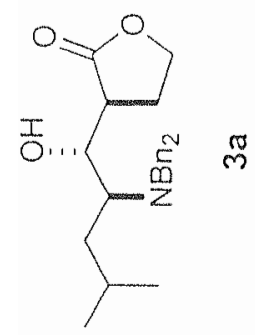

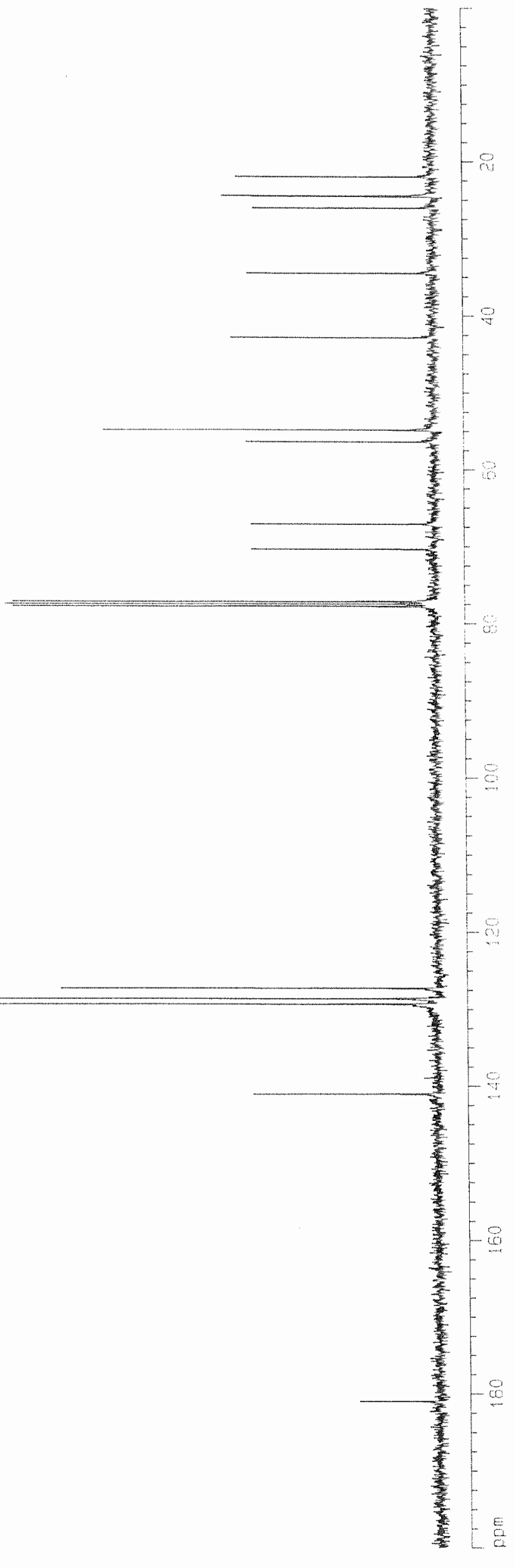




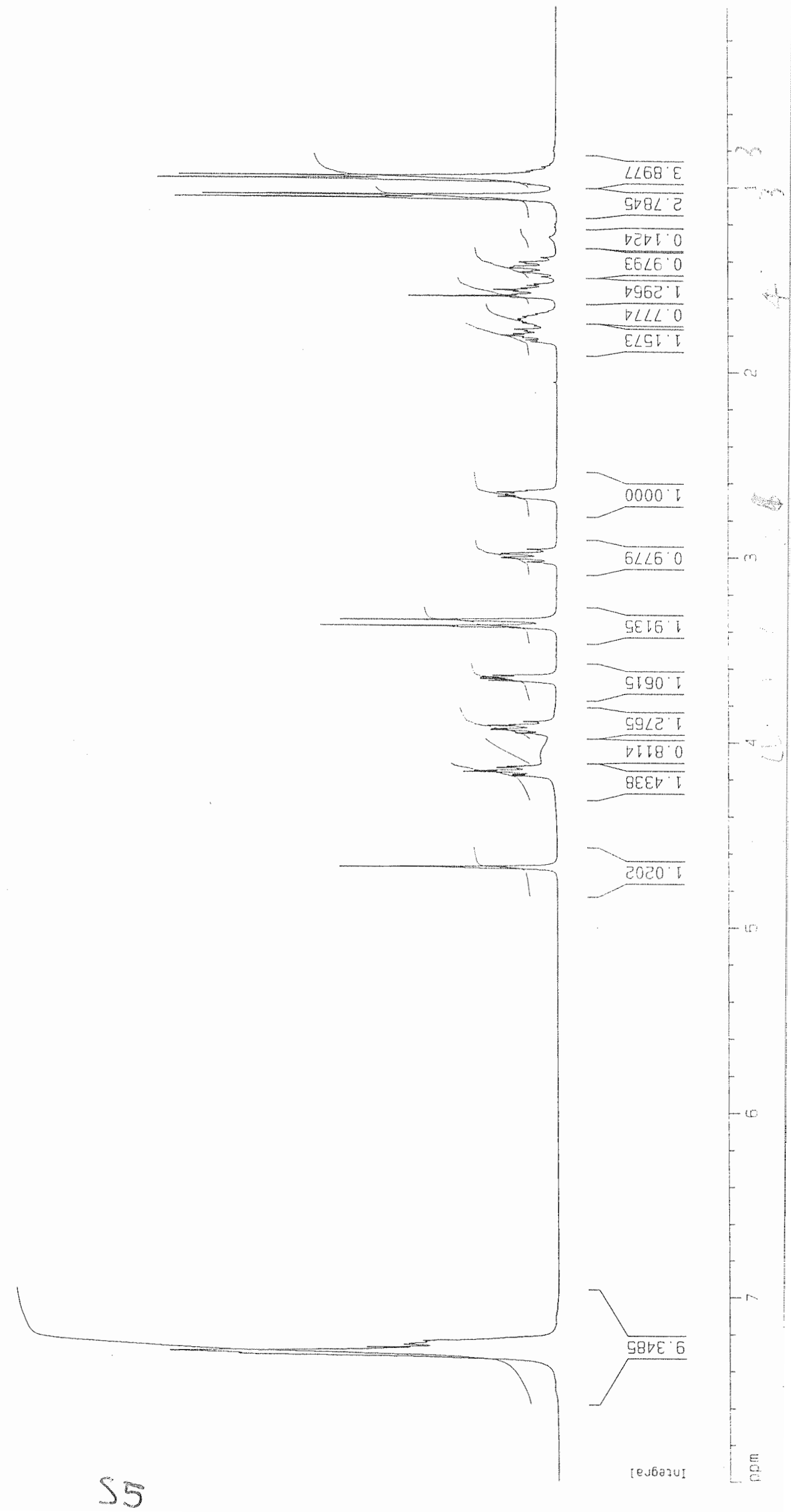




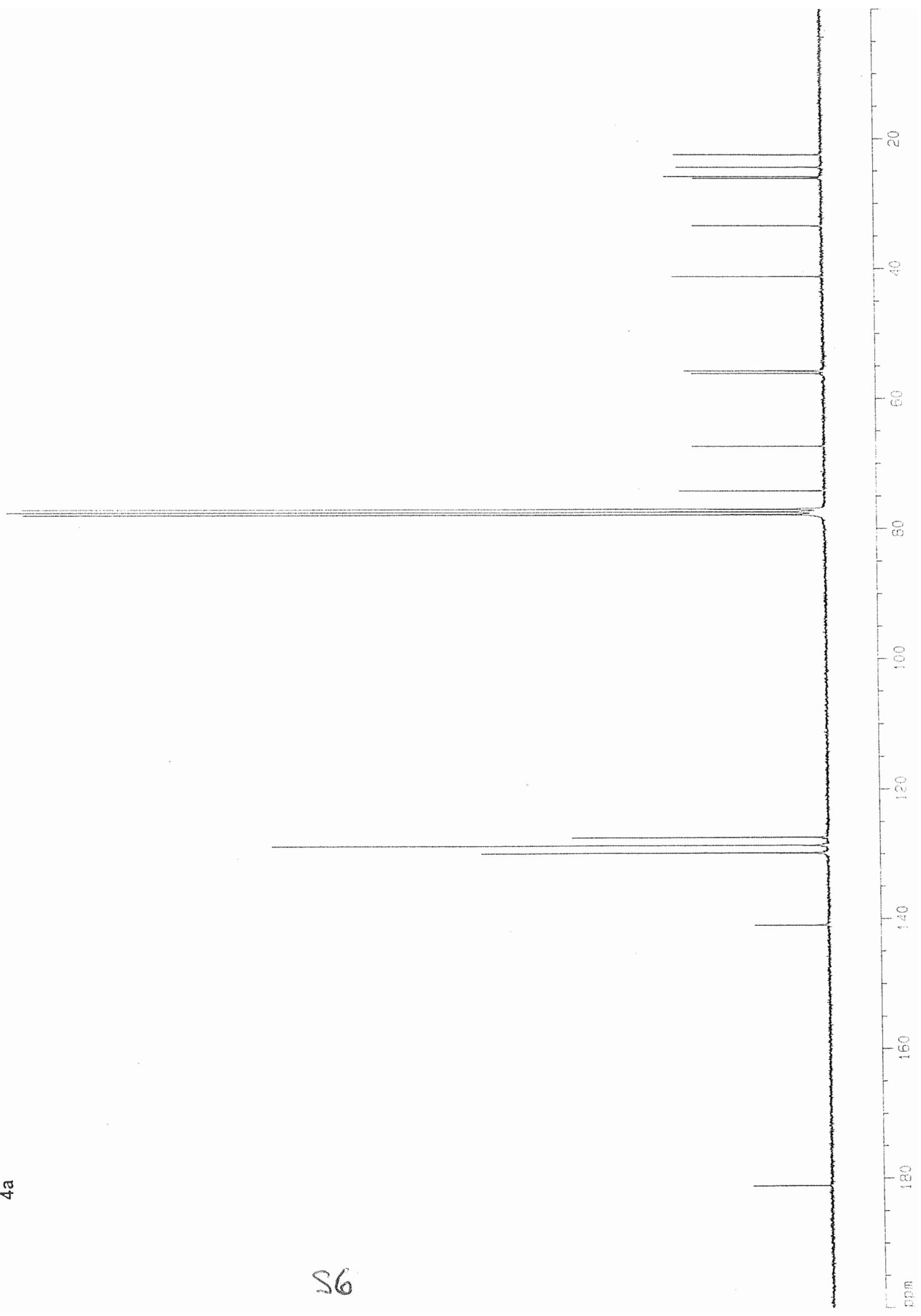




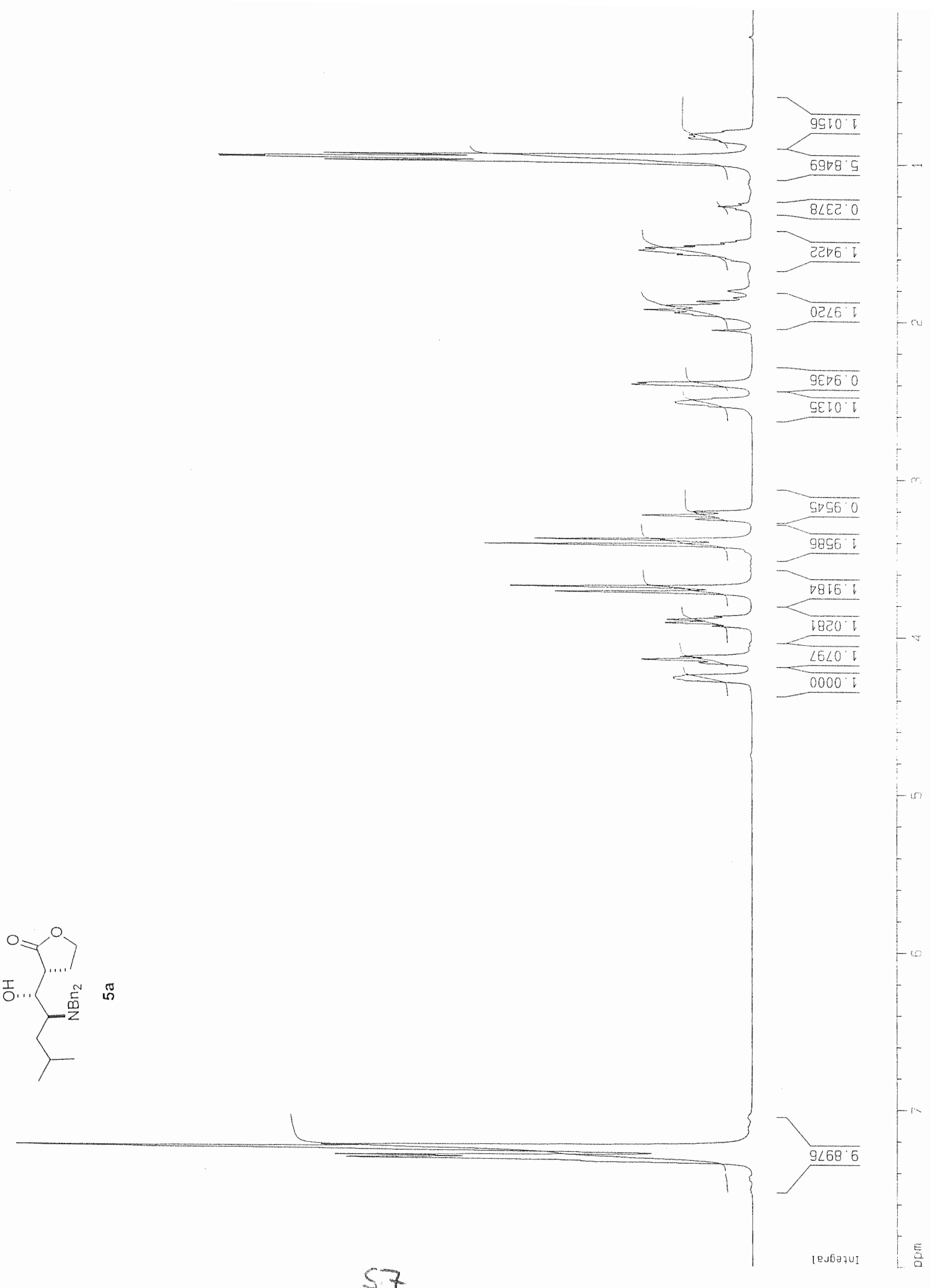




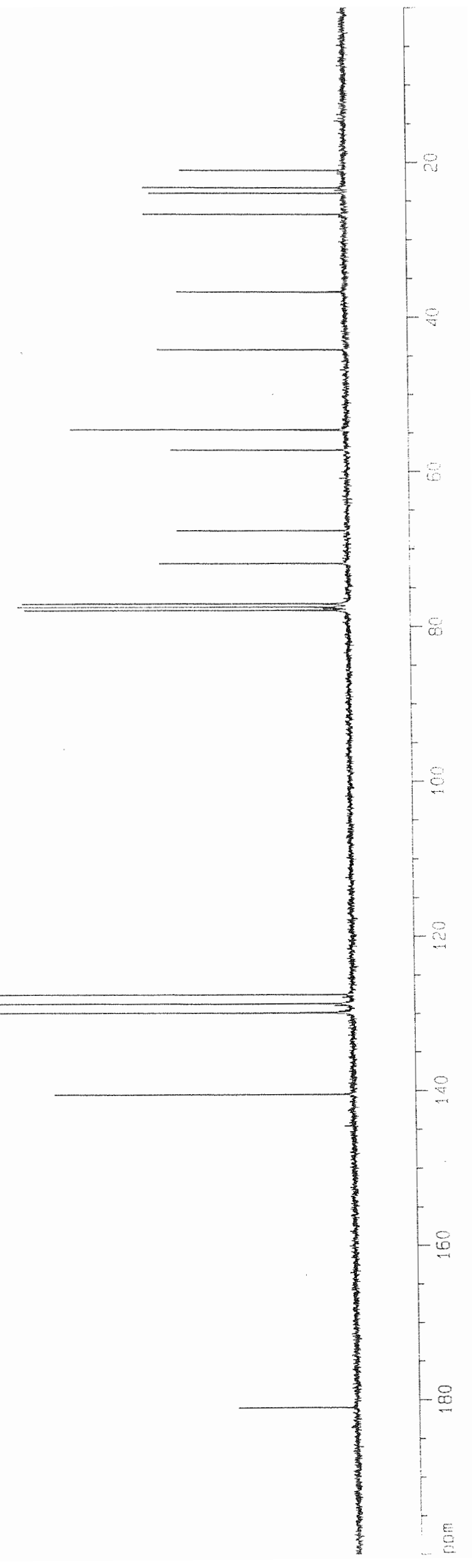




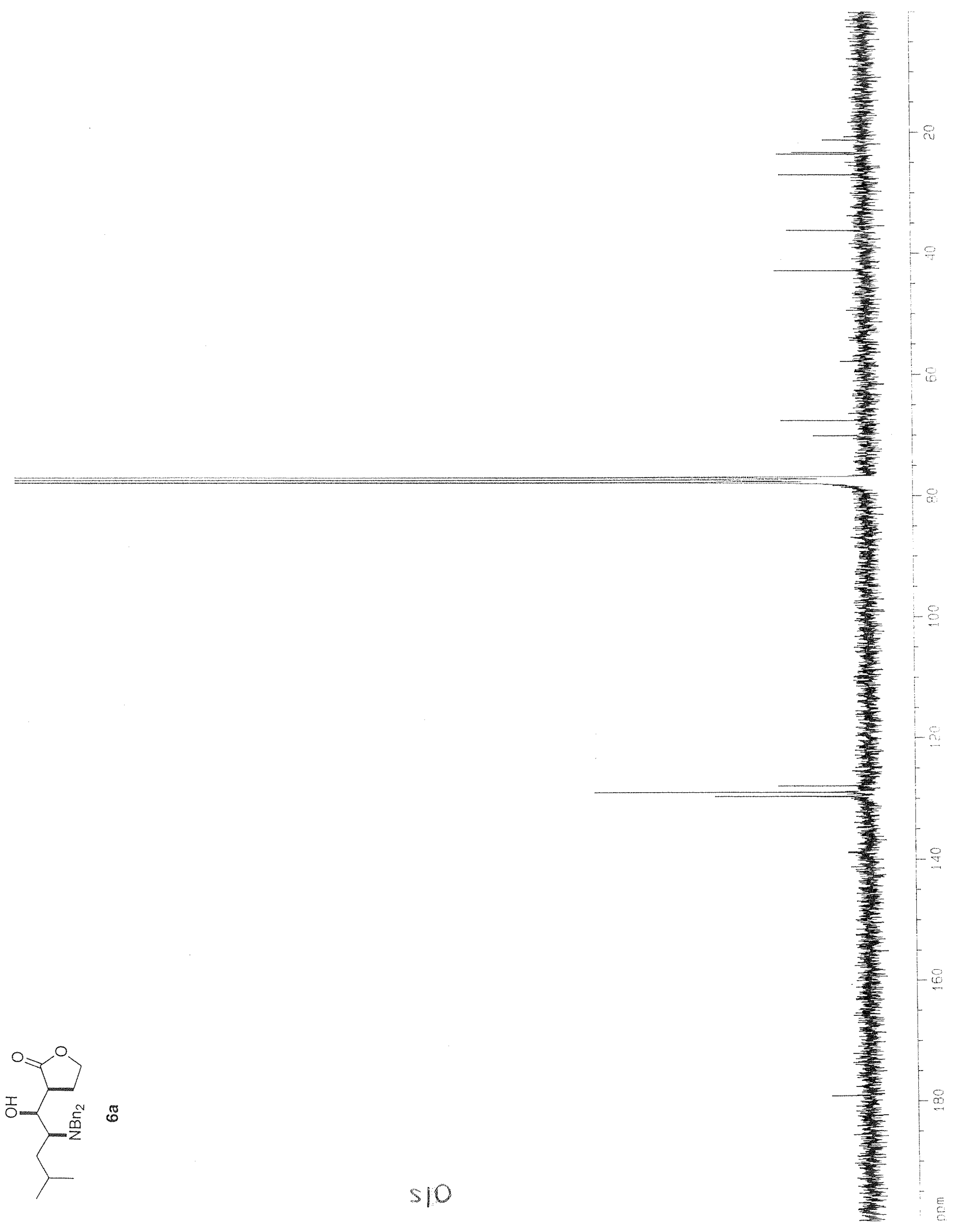




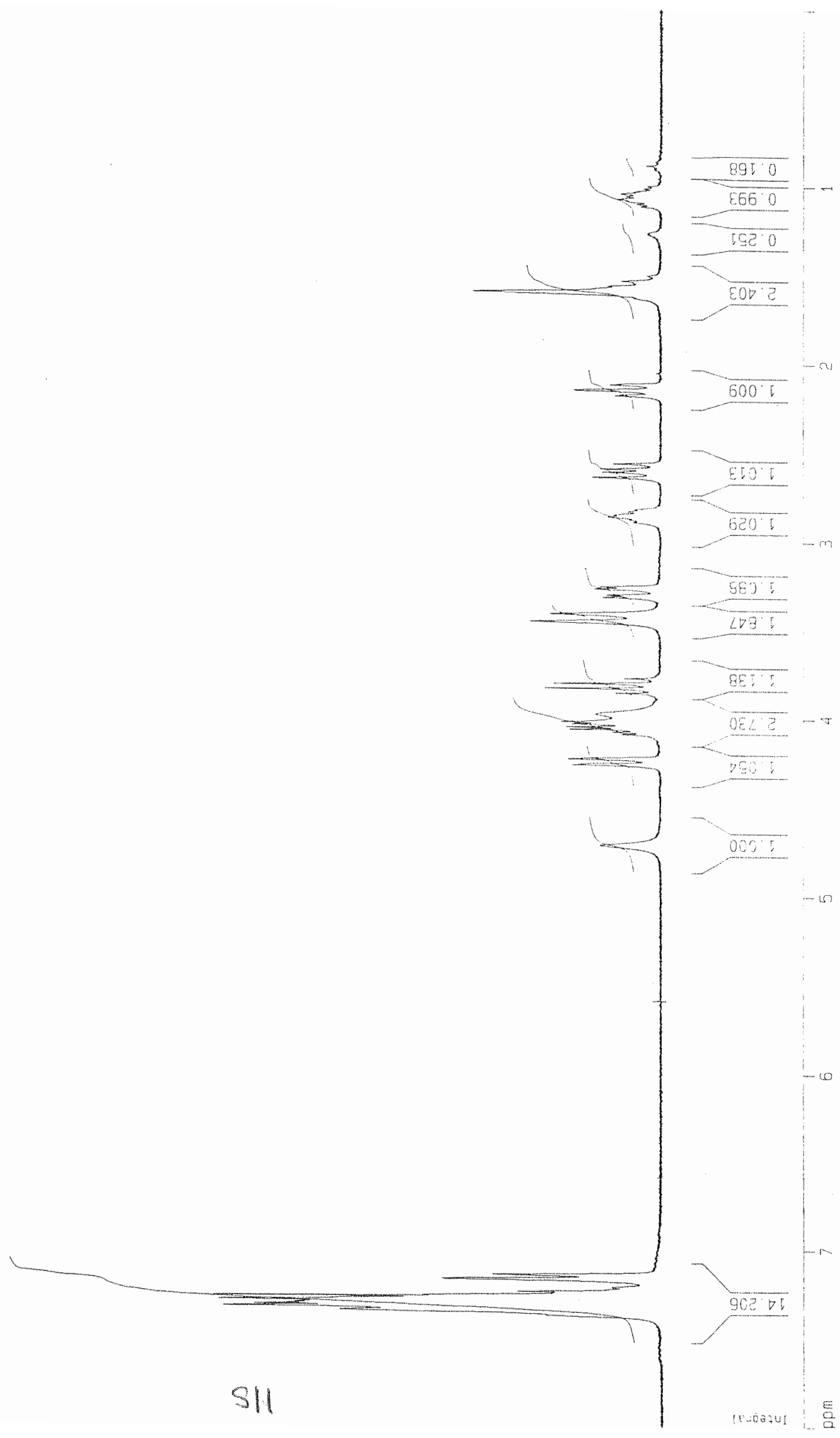




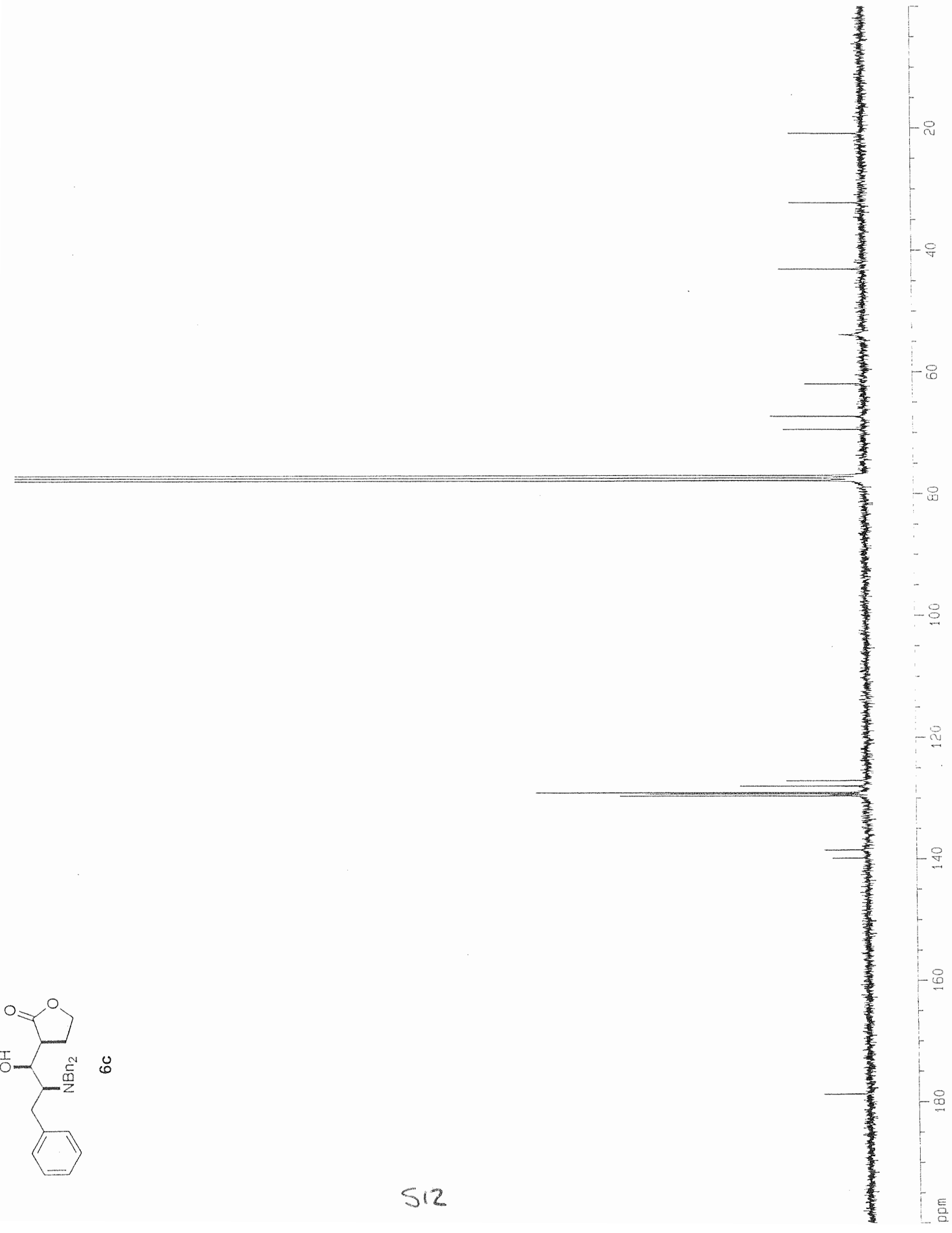




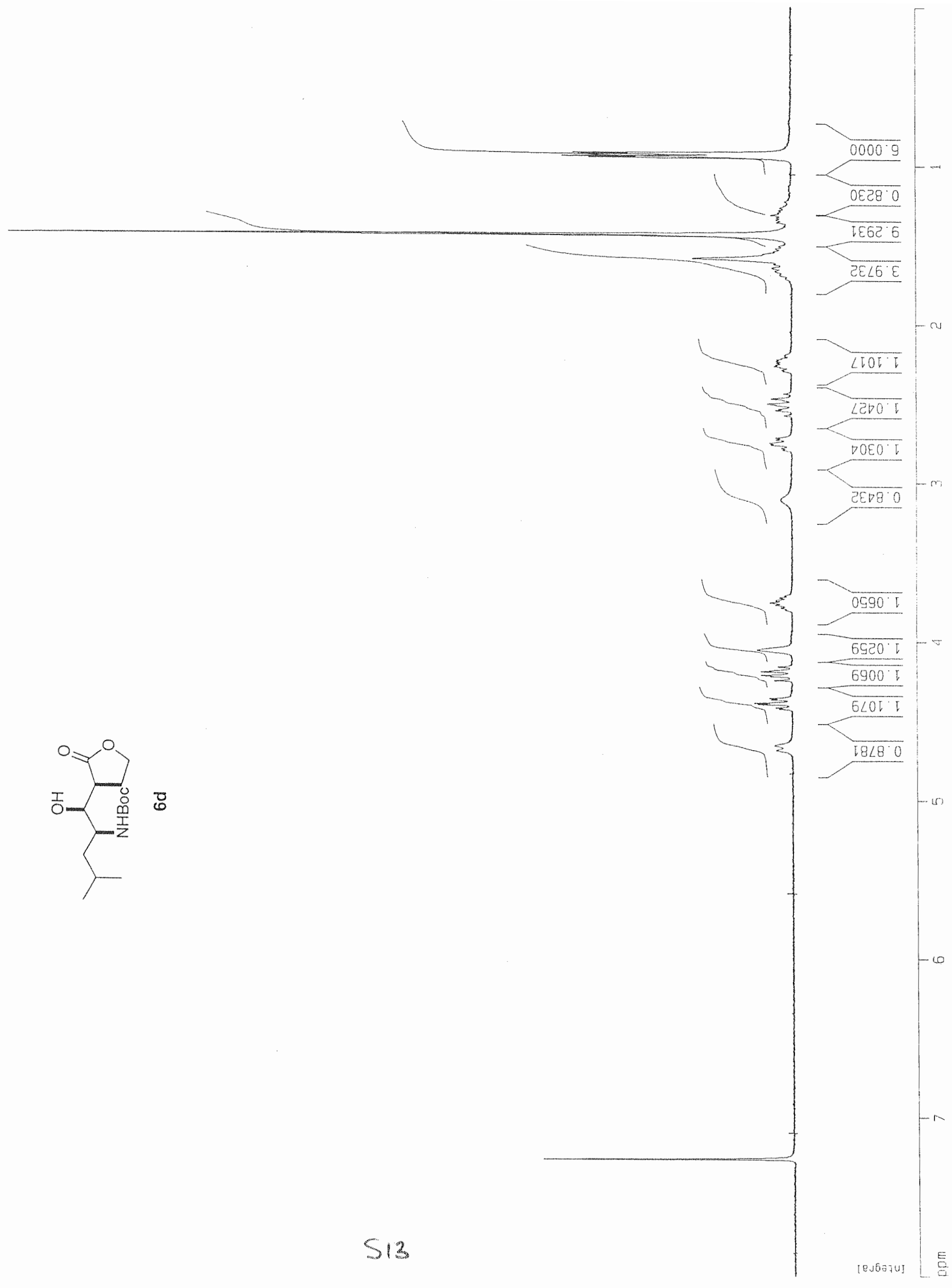



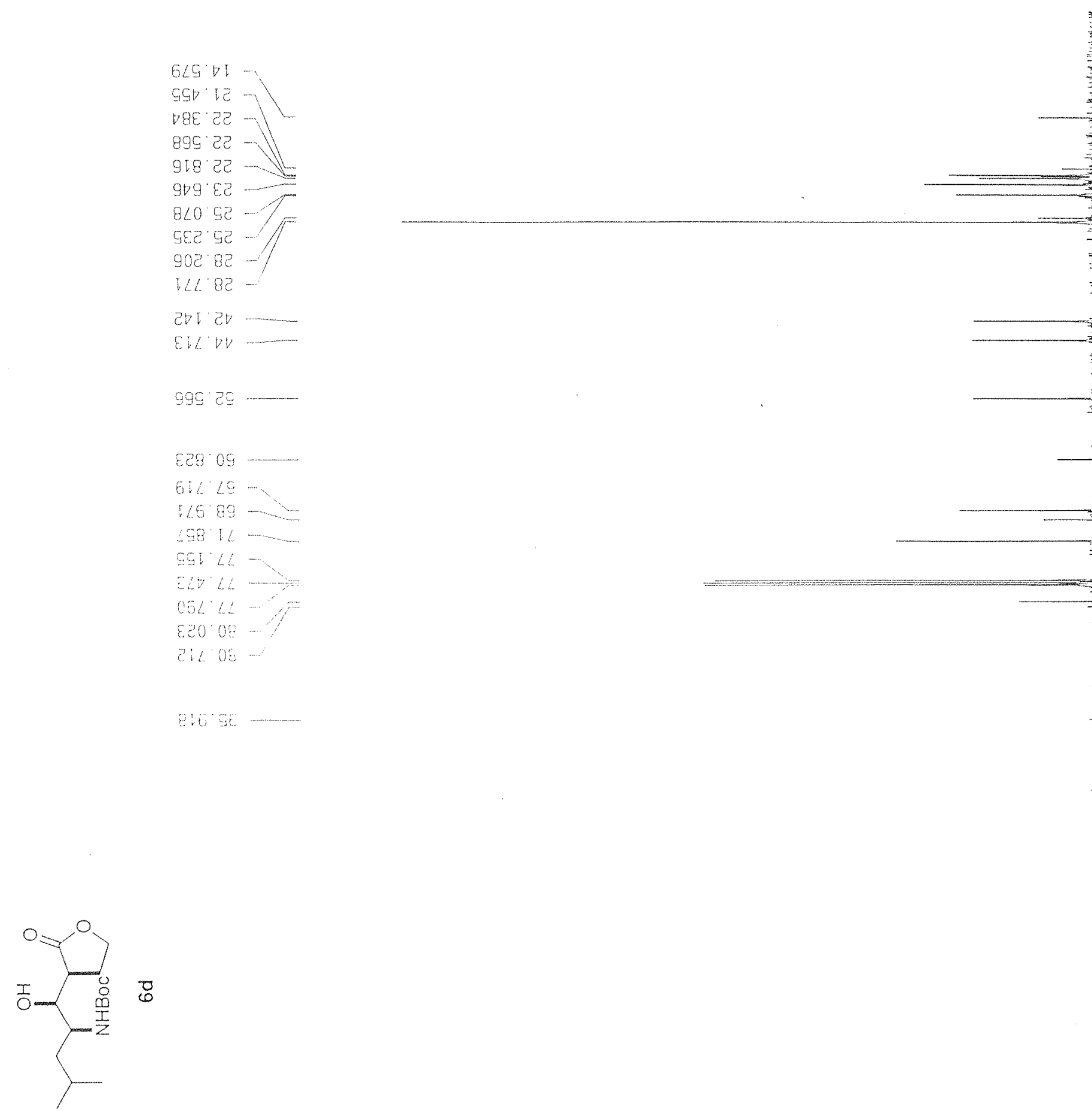

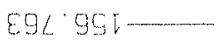

$8926 \angle L$ 


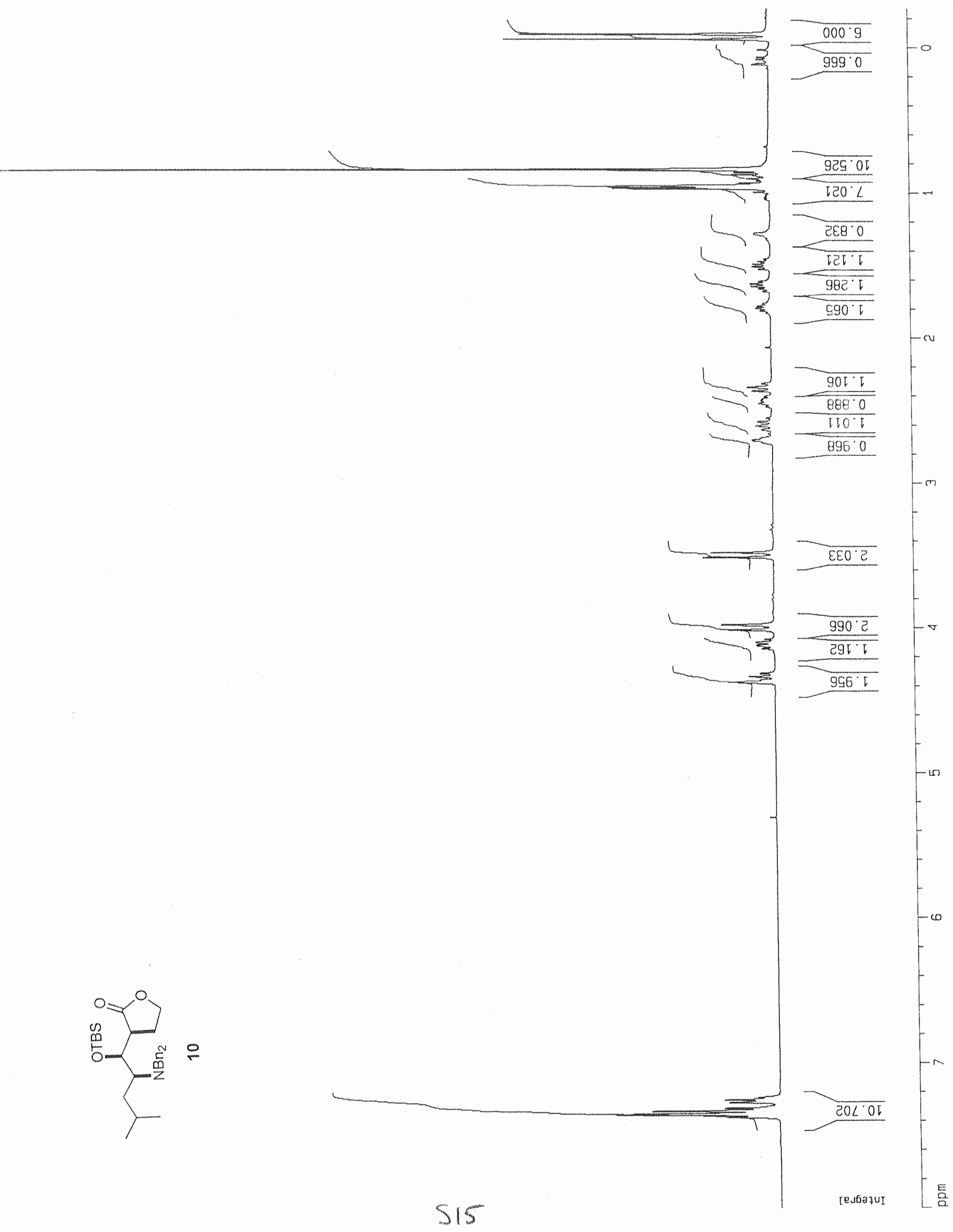



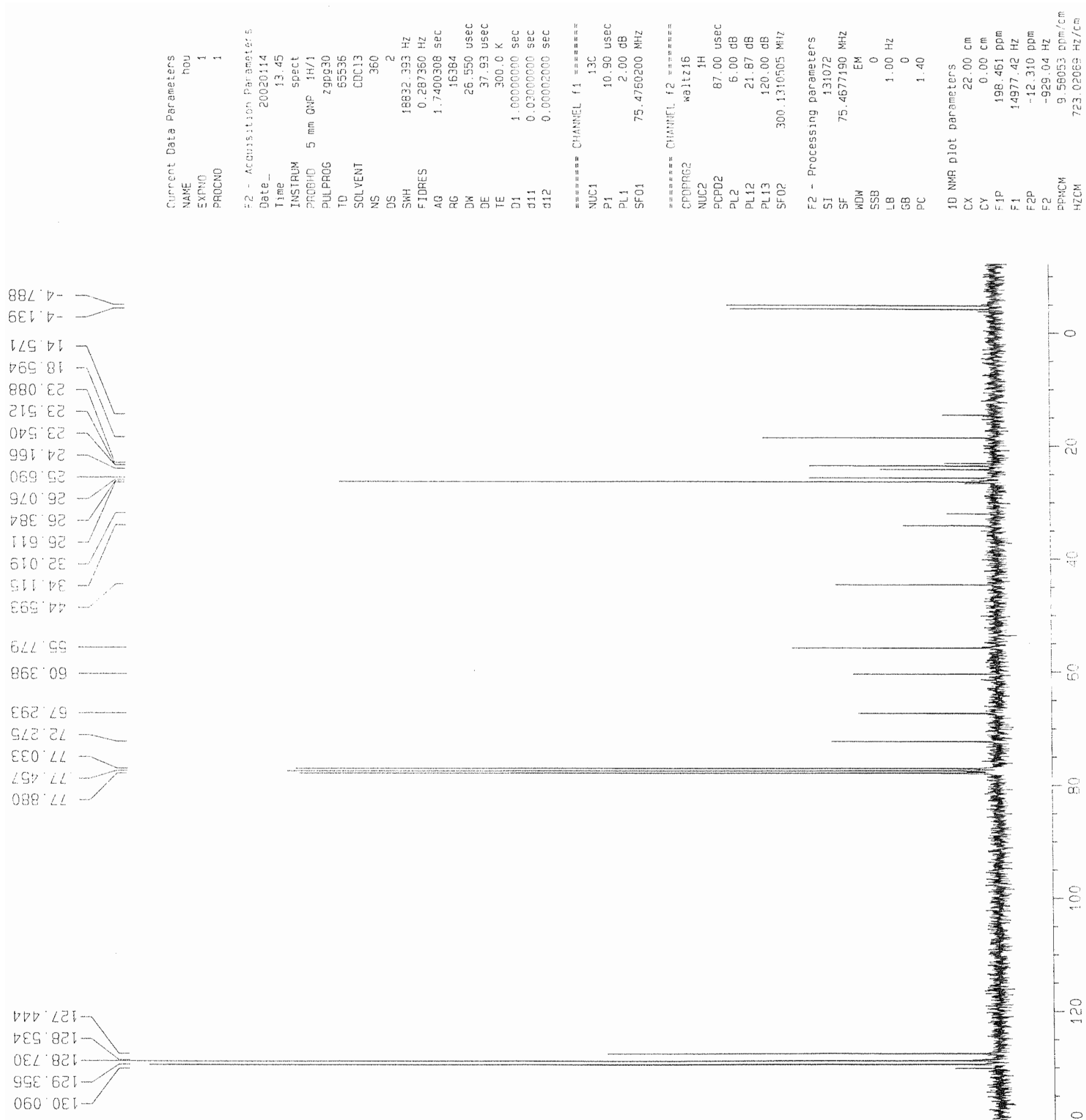

$299^{\circ} 05$

$810.081=$

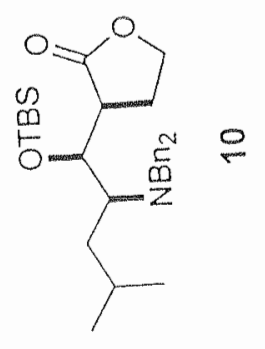




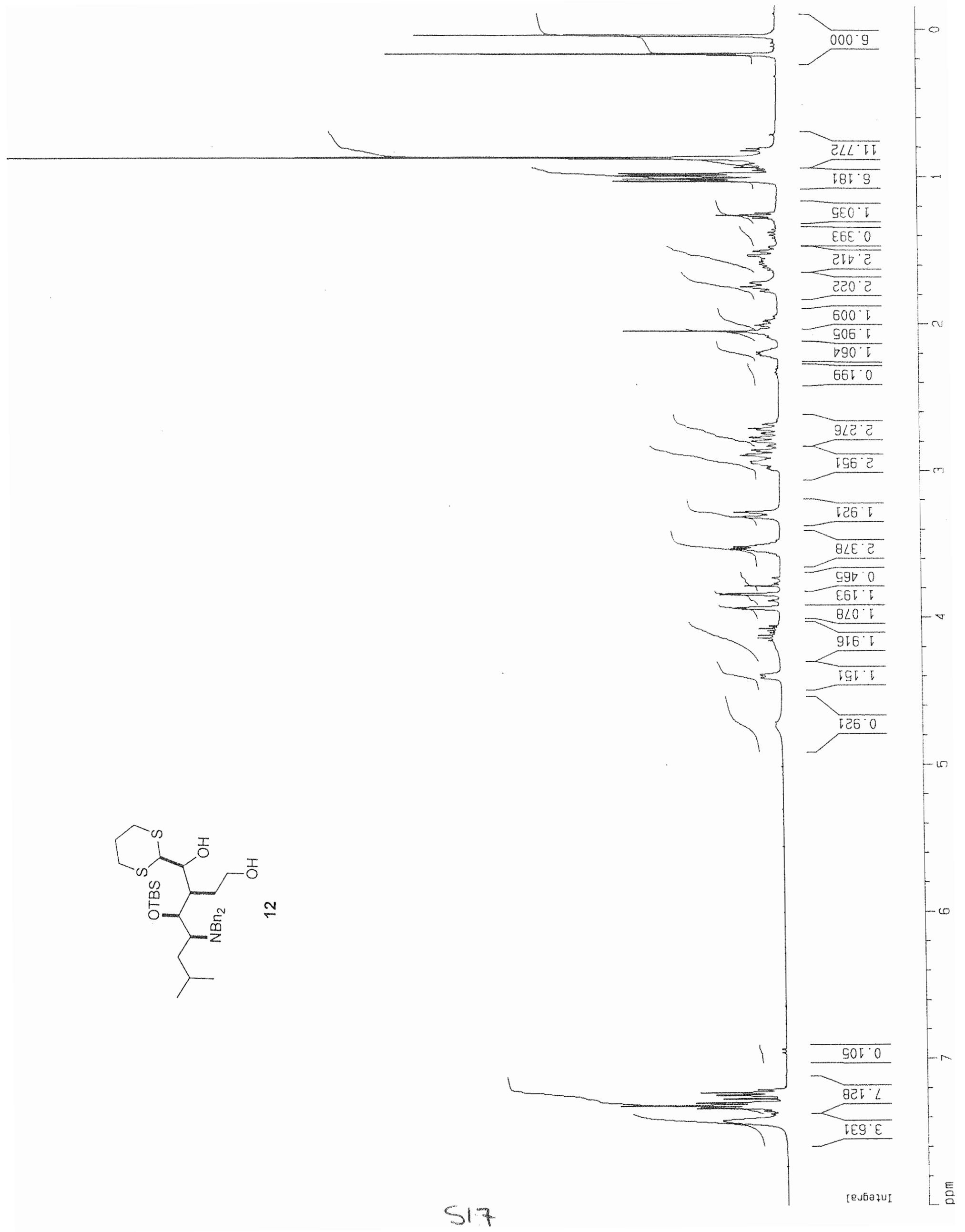



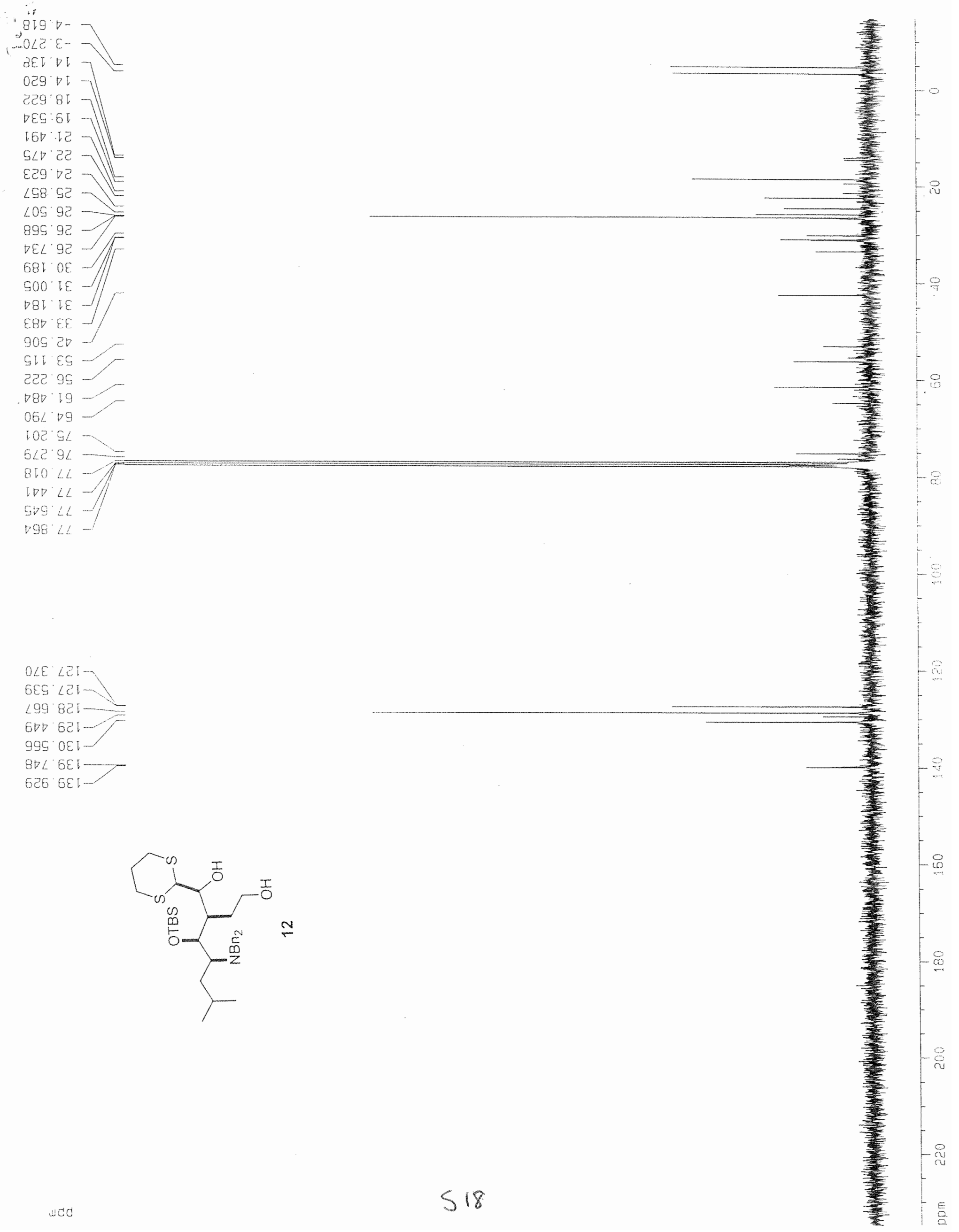


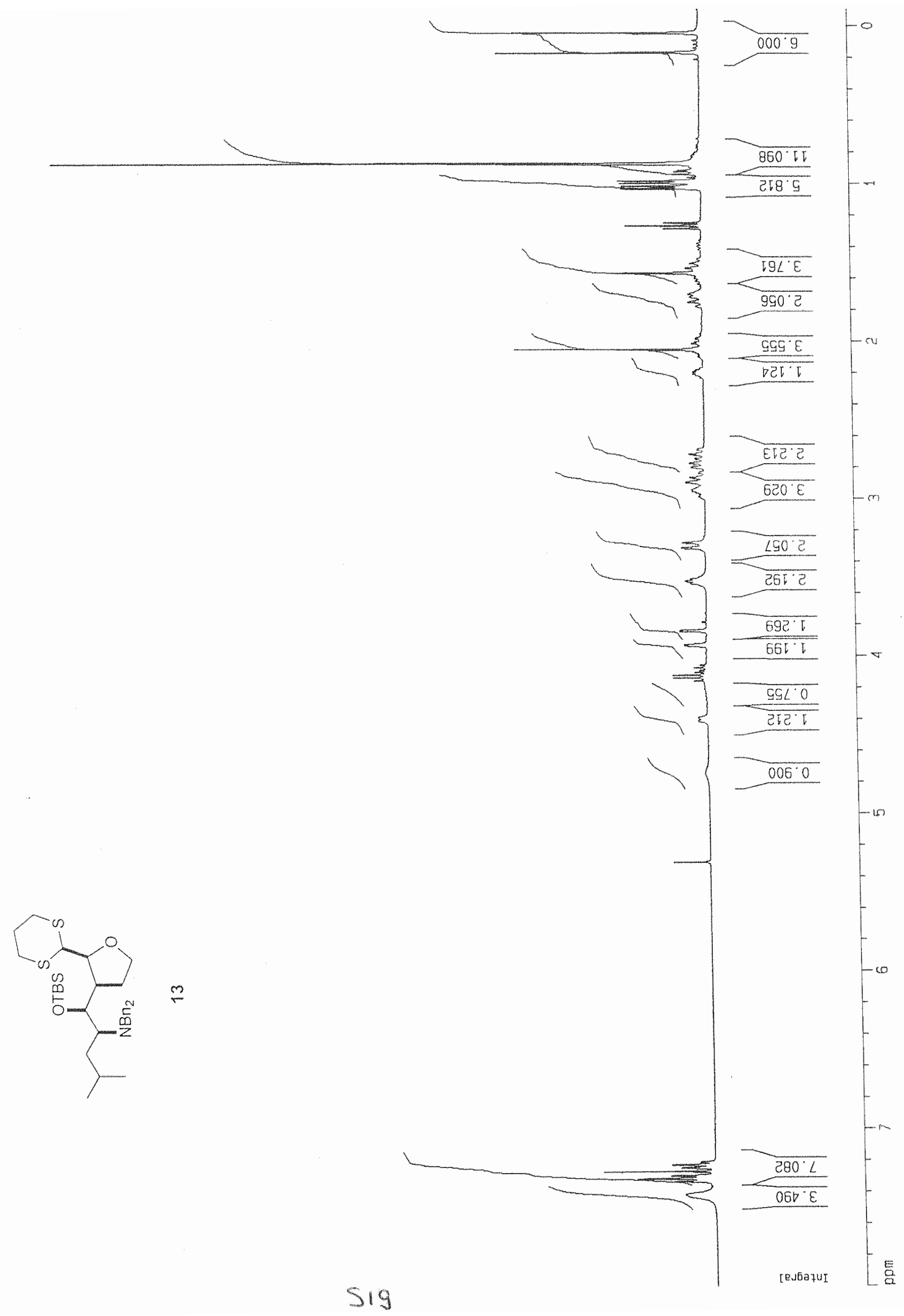




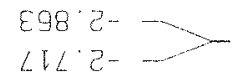

51681

916.22

989.

टEL $S Z$

86652

$\varepsilon 9992$

18905
$600+2$

EDT IE

$695 \mathrm{ce}$

Oटः 97

SES:

cor 99

EL $\angle S \quad-$

$080^{\circ} 69-$

WLEL

$100 \angle L$

0284

seg $h$

Bषe

19908

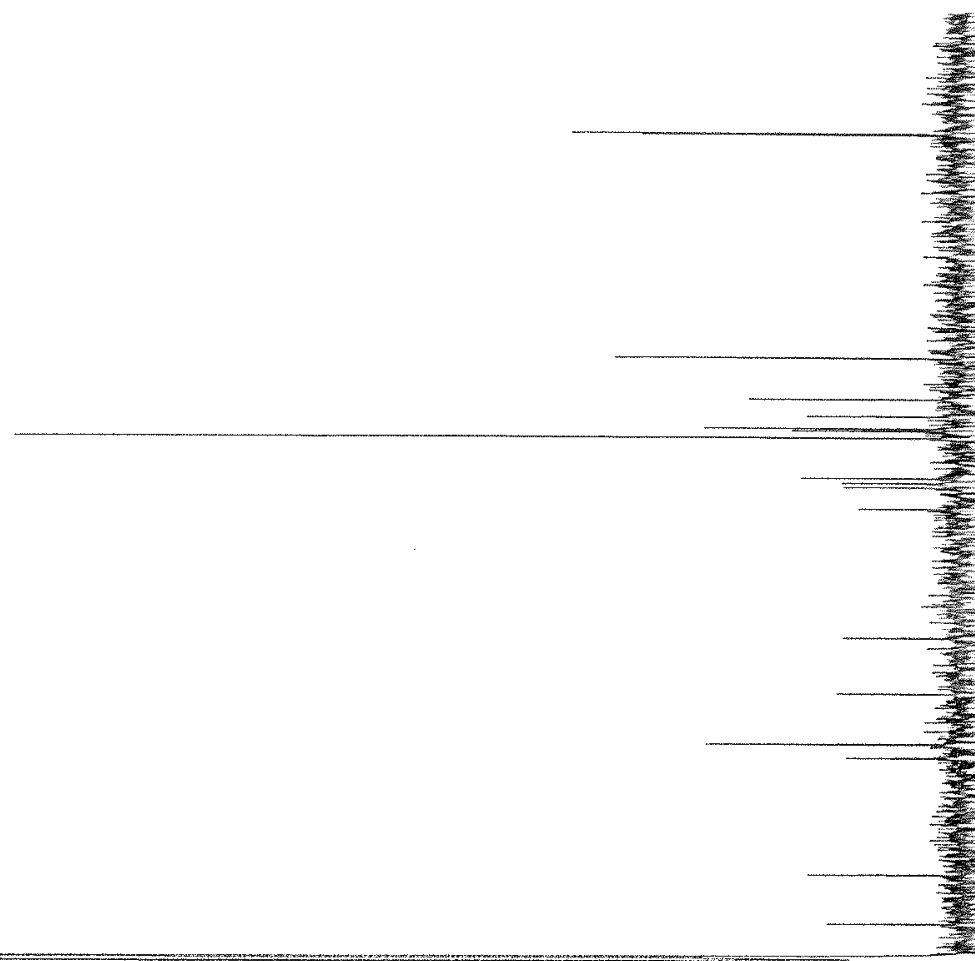

69E /ZI-

$879821 \cdots$

D十L 62, ...

$980^{\circ}$ in

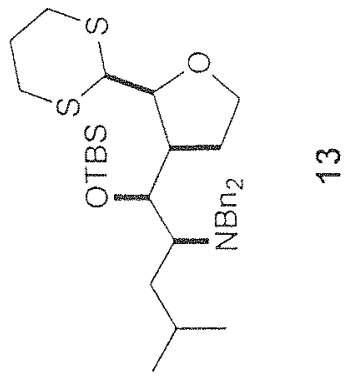




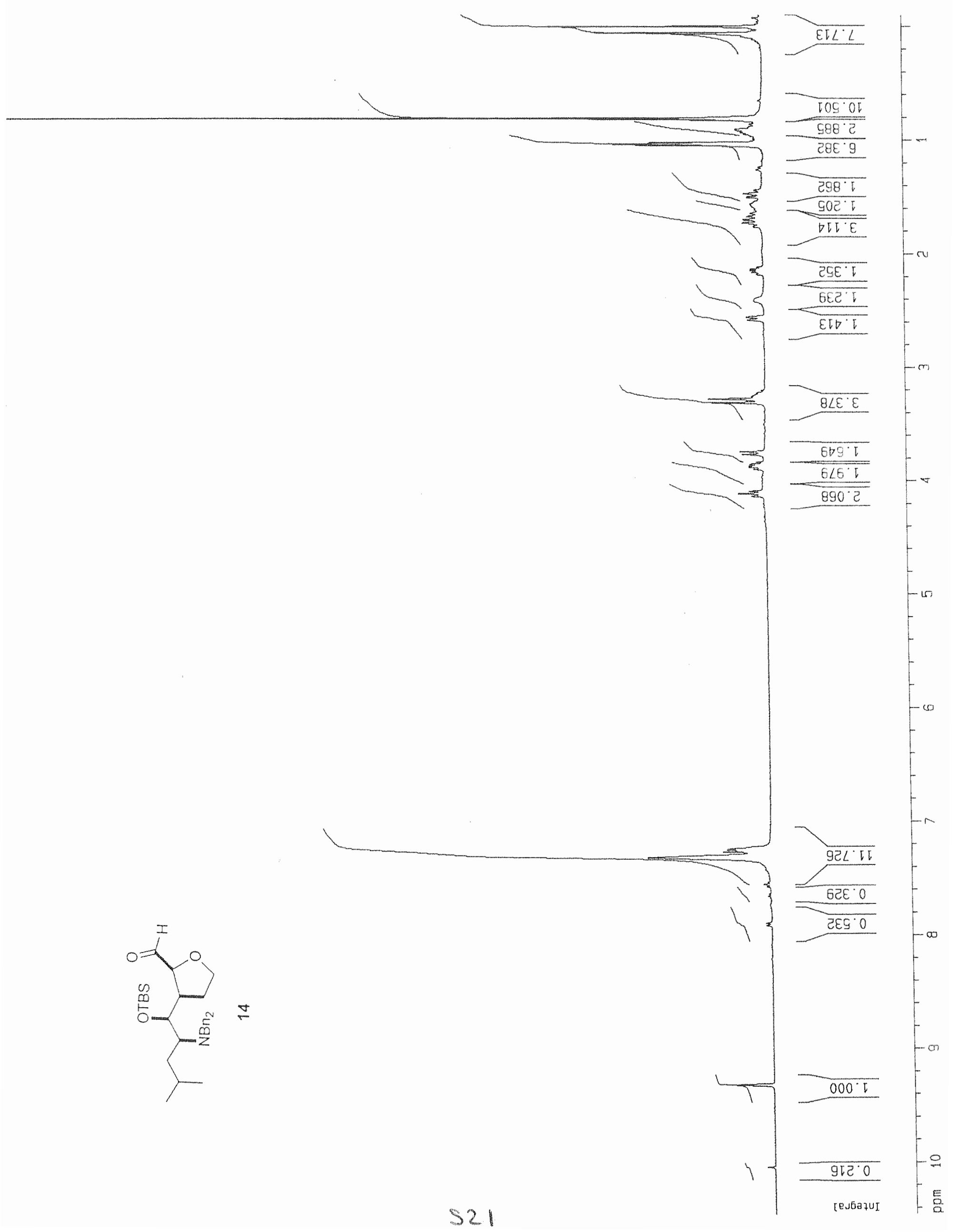




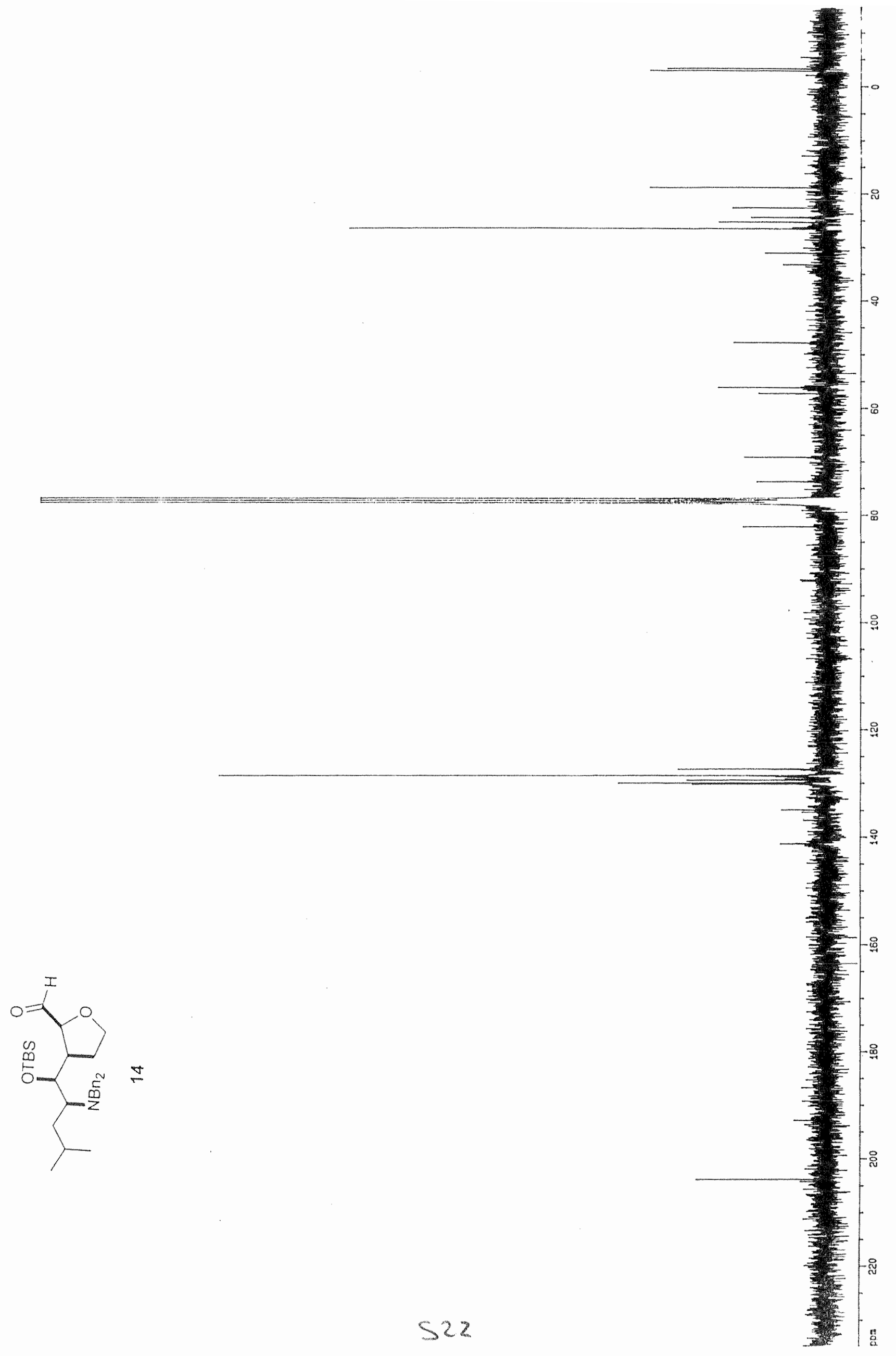




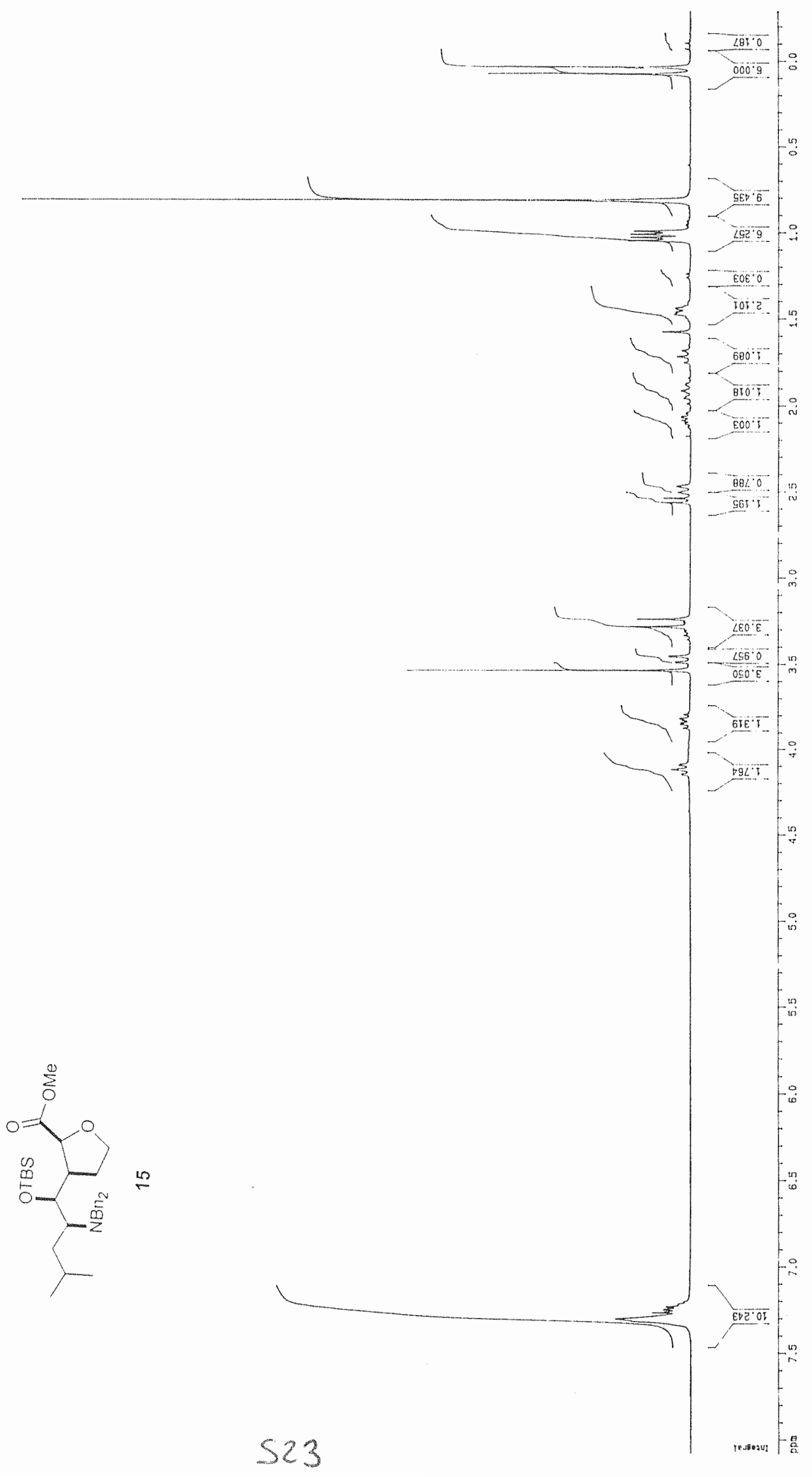


$896^{\circ} \varepsilon-\longrightarrow$
$896 \cdot 2-\longrightarrow$

$996 \cdot 85$

$0 \angle D^{\circ} \mathrm{ZC}$

एटG

口TD $G$ TE

9.9.9?

$289^{\circ} 62$

OSD $E E$

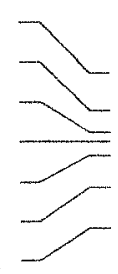

$86 \angle 95-$

$175^{\circ} .9$

$962.99-$

6टE $\angle 9$

$9 \angle 0.69$

$966^{\circ} \mathrm{O}$

gा

GEV $L t$

$E S L L L$

EIE $\angle Z I-$

टटG $8 \mathrm{~d}$

पDE 625

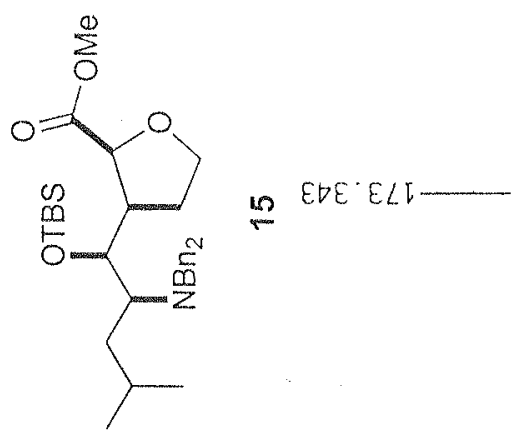




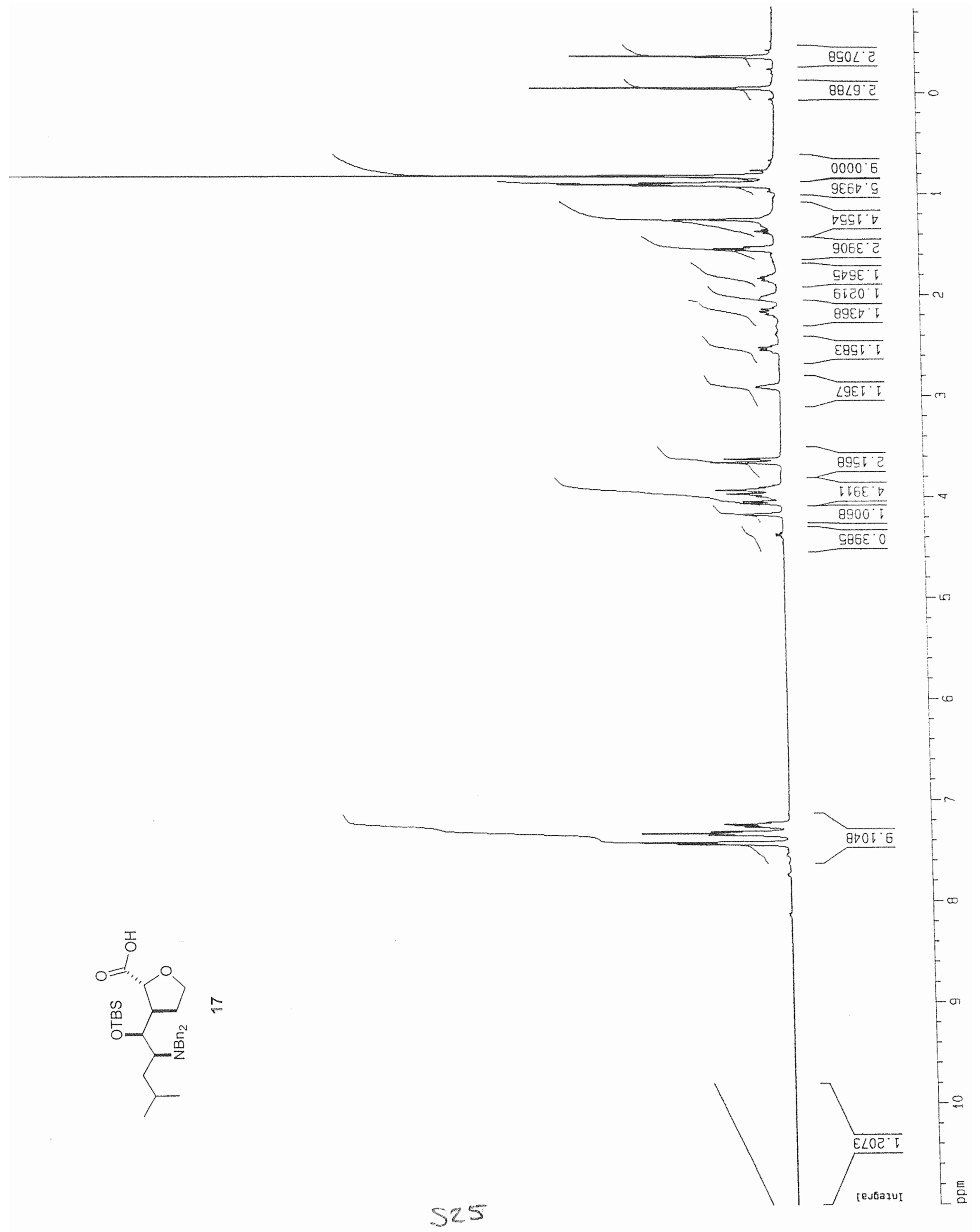




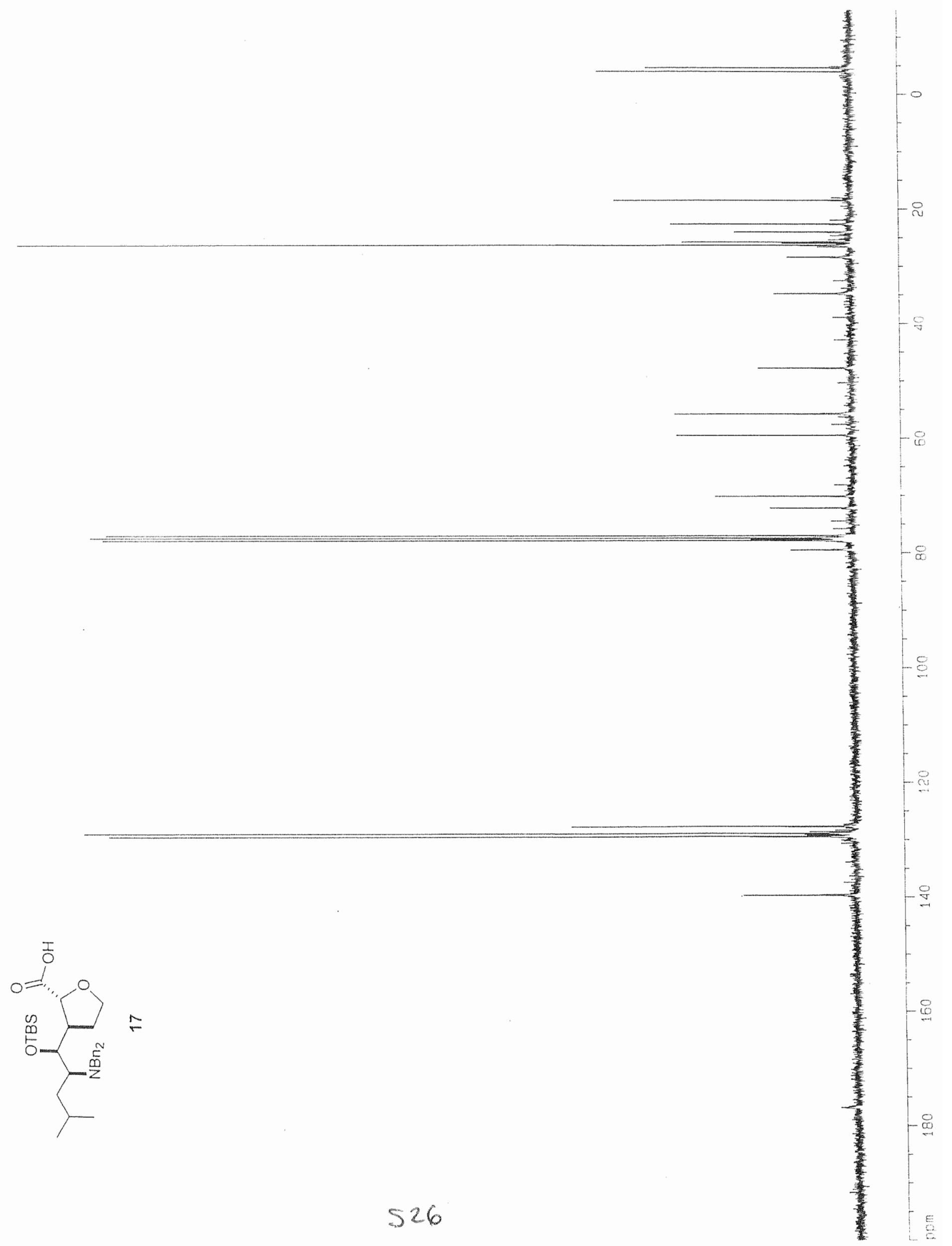




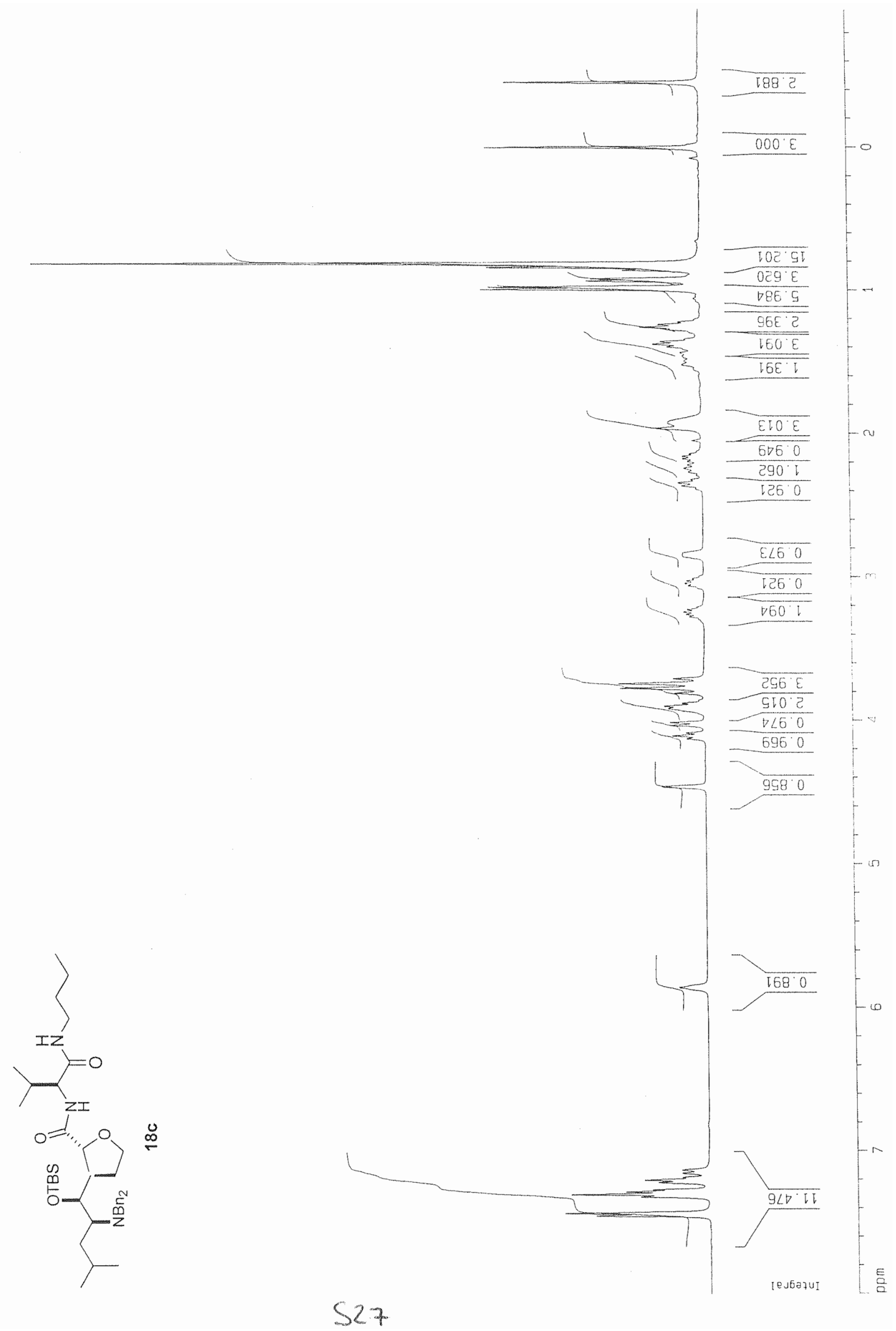



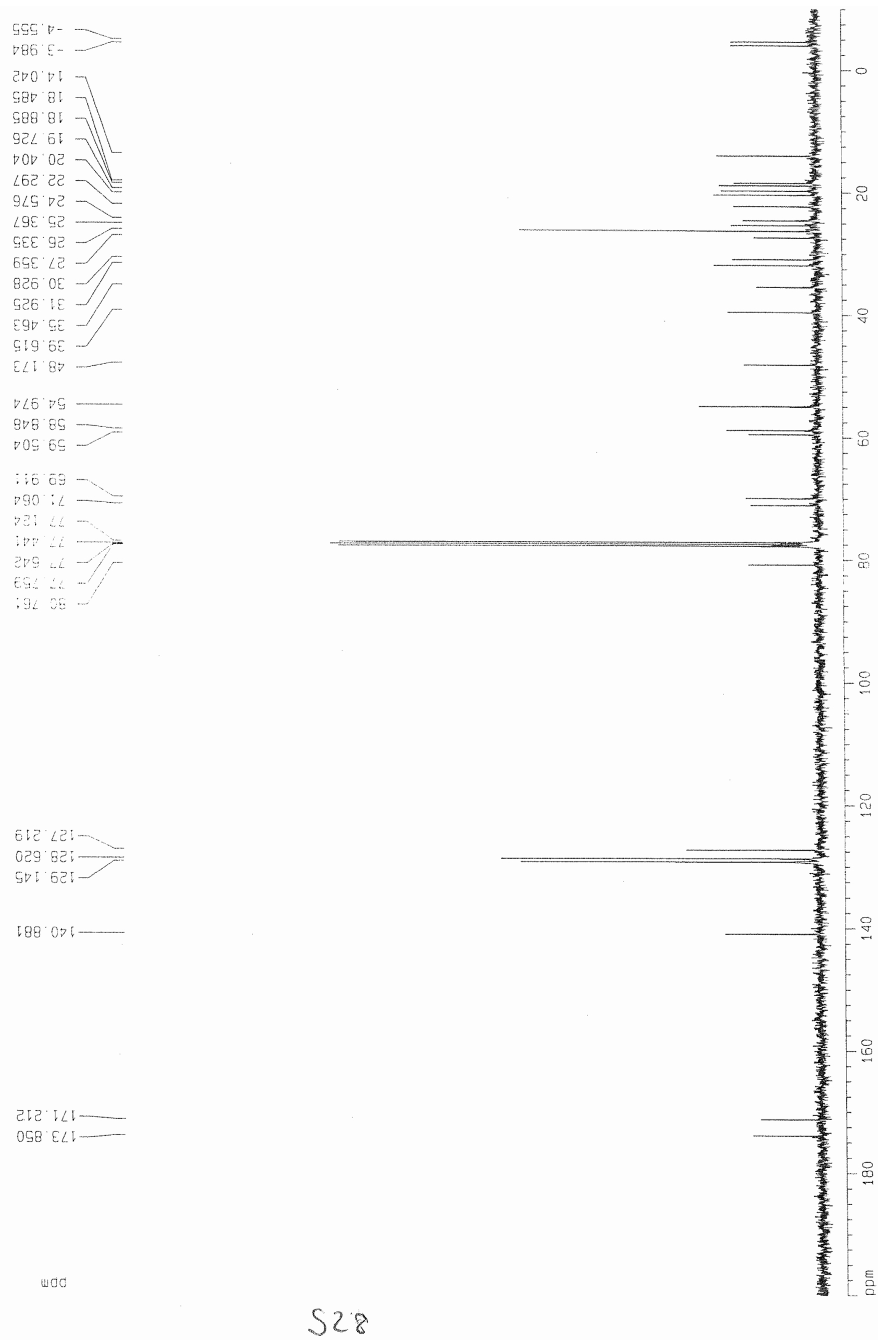


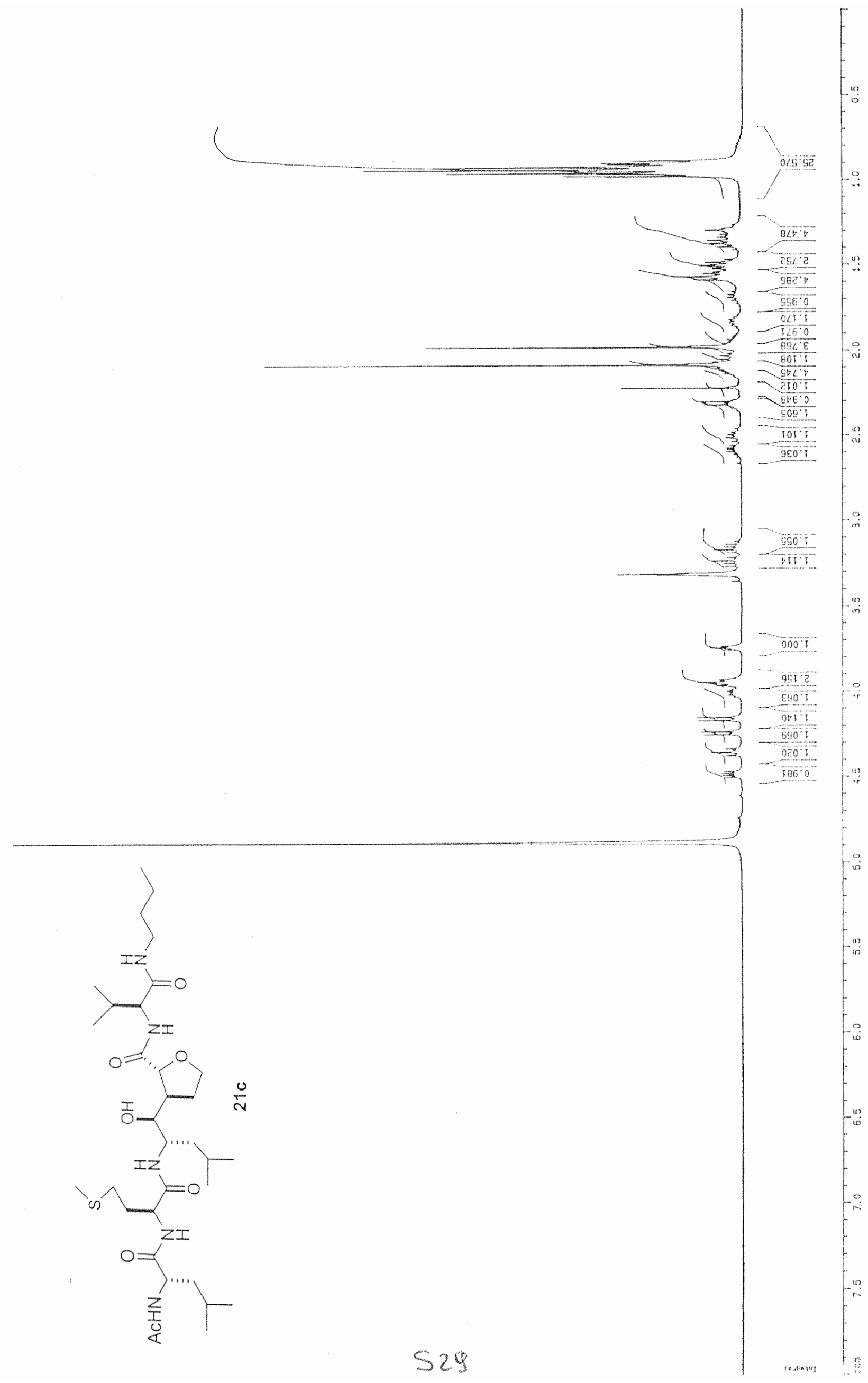




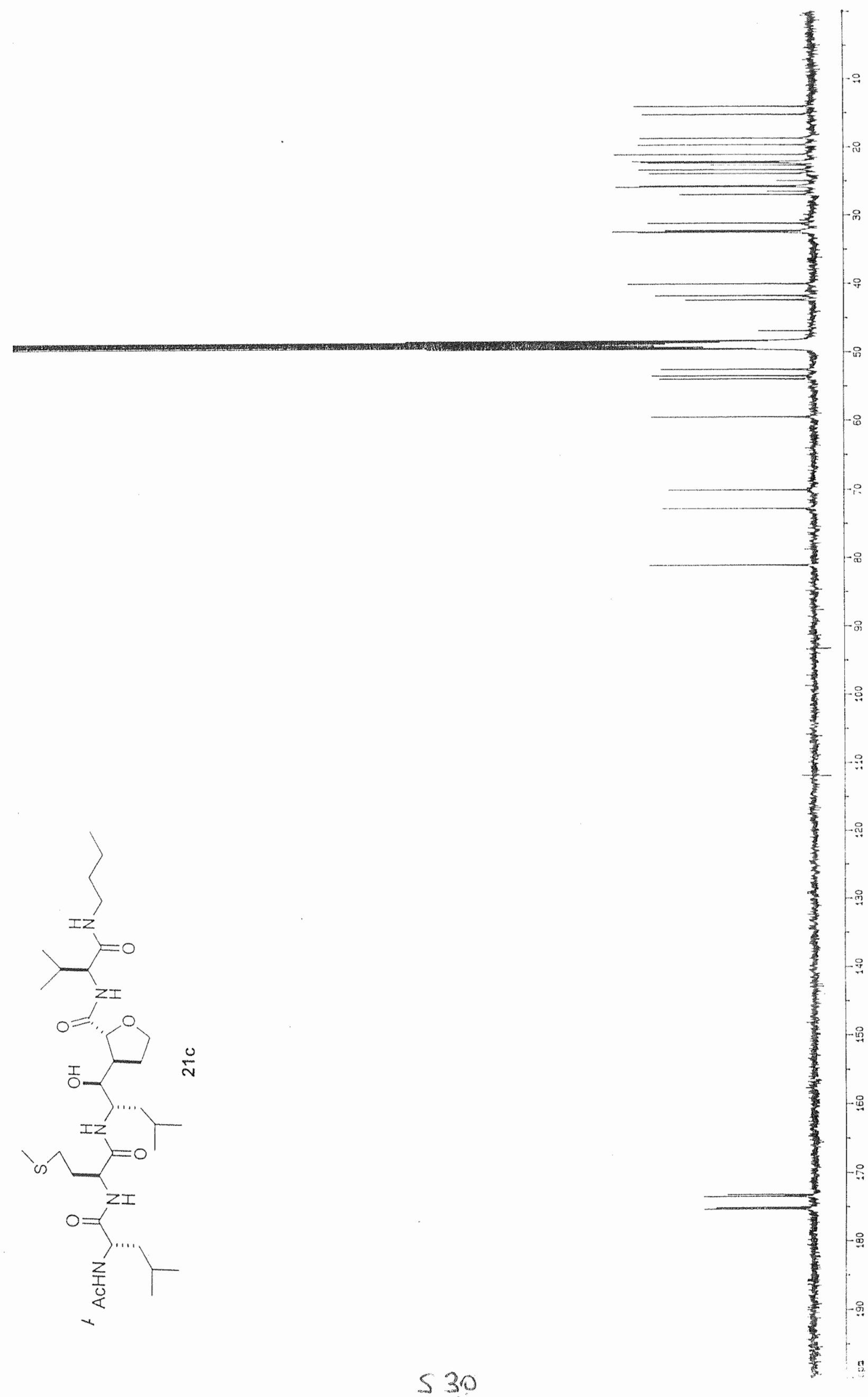




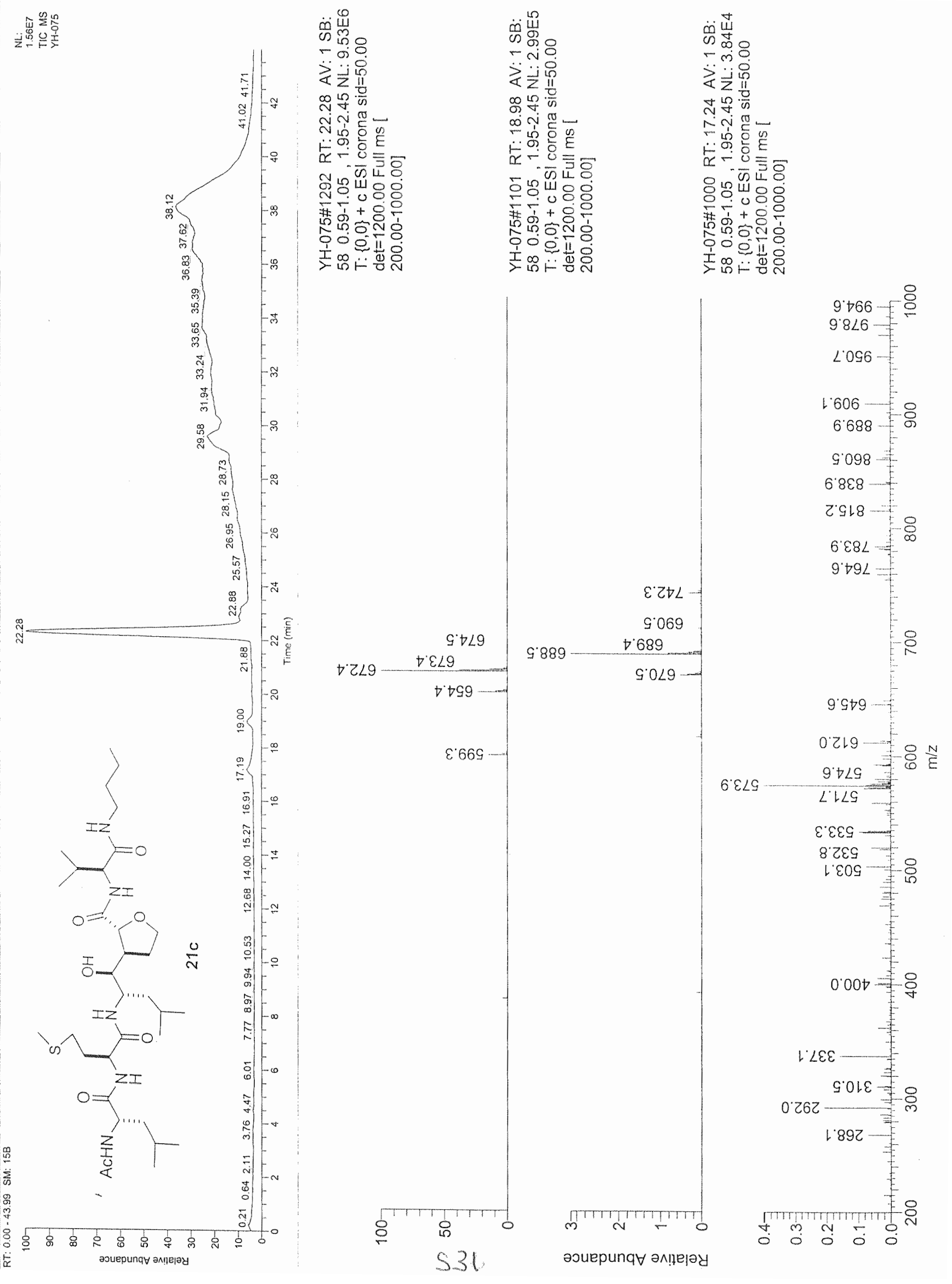

